\title{
Distribution Effects of Labour Deregulation
}

\section{Fred Argy}

W ell-designed liberal reforms can deliver substantial improvements in employment and average living standards. And many prove good for the poor as well as the economy. However labour market deregulation, while positive for the economy, has tended to disadvantage poorer workers (at least relative to alternative methods of enhancing workforce participation). It presents a classic efficiency/equity trade-off - 'efficiency' being about improving aggregate utility while equity is about the distribution of utility gains. This tradeoff is the main focus of the paper.

The 'equity' problem for labour market policy-makers is compounded by the fact that unskilled workers have for some time been the main losers from technological change, which has tended to be skill-intensive, and from globalisation, with the increased integration of China, India and other developing economies into the world trading system and the growing practice of off-shoring business services. Adjustment costs tend to be higher for trade-displaced workers than for other job losers (Martin, 2006).

In such an economic environment, governments contemplating further labour market deregulation will be looking for advice from economists on how they can tap the potential economic gains while minimising the pain for poorer workers.

The paper starts by outlining how reforms relating to labour markets can impact unevenly on distribution and in particular on the job security and relative earnings (or both) of many unskilled workers. The paper then discusses four ways economists can respond to the distribution dimension and the main attributes and drawbacks of each. It ends up eliminating two of the options on various grounds.

The next major section of the paper focuses on the fourth response ('efficiency and equity') and argues that it is potentially superior to the first ('efficiency only') because it can perform as well on the criteria of employment and productivity (output relative to inputs) - and yet produce less social inequality. The fourth substantive section of the paper introduces other elements of 'equity' (besides income distribution) into the evaluation. When this is done, the bottom-line verdict becomes more open to value judgment.

The final section of the paper sums up the findings and discusses the appropriate role of economists in tackling equity-efficiency policy conflicts.

\section{Distribution Effects of Neo-liberal Labour Market Policies}

Efficiency enhancing reforms - those where winners outweigh losers and can be presumed to increase aggregate utility - are often socially progressive. This is

The author was a high level Federal policy adviser in the 1980's and 1990's. Since retiring in 1991, he has written extensively on the interaction between social and economic issues. 
true for example of reductions in tariff protection on goods widely consumed by low income households and the removal of many of the old forms of financial regulation such as on housing, which had largely perverse effects on distribution. But reforms which involve labour market deregulation and which are associated with reduced welfare-access often have regressive redistribution effects and cause transitional adjustment pain as well as economic gain. We will call such neoliberal labour market policies NLM for short.

NLM is about promoting more structural wage flexibility, encouraging a shift from collective bargaining to individual contracts and giving managers greater discretion in the deployment and remuneration of staff, including greater ability to outsource and export jobs and to secure foreign labour such as guest workers. It has the effect of weakening the policy umbrella of workers' protection (through awards, unfair dismissals legislation, trade unions and immigration controls) previously available to many low-skilled workers.

Labour market deregulation is usually associated with tough welfare regimes. Measures which make welfare access more difficult for able-bodied people, such as no-payment penalties for participation failure (recently applied to sole parents and people with disabilities for the first time in Australia), make it more difficult for job seekers to refuse an unappealing job or refuse to sign an individual agreement. Their effect is to further increase the bargaining power of employers relative to vulnerable employees (those without bargaining power).

In short, in this paper, NLM refer to labour and welfare policies which seek to minimise:

- government involvement in wage determination (for example, setting a very low statutory minimum wage relative to median earnings),

- levels of worker-protection regulation (for example, on unfair dismissals, severance payments and hiring practices),

- welfare benefits for persons of working age relative to median earnings; and

- $\quad$ the role of trade unions in the market place.

The Howard Government's recent reform package known as 'WorkChoices' and 'welfare to work' represents an attempt to more fully embrace NLM policies (although it does not go as far as the US model in some respects, such as minimum wage regulation and welfare access).

The evidence is strong that NLM tends to increase earnings inequality. Countries with the highest levels of market income inequality (pre taxes and transfers) are those with relatively deregulated labour markets (Luciforo, 1999; Borland, 2000; Saunders, 2002:197 and 252; Forster and d'Ercole, 2005; Argy, 2006:62-67; J encks, 2006). One study (Luciforo, 1999) found that over 60 per cent of cross-country differences in earnings differentials can be attributed to institutional arrangements on wage regulation, the role of trade unions and the structure of collective bargaining.

Deregulation also exposes many workers to greater income uncertainty and reduces their capacity to achieve their desired working hours and work-family balance - a quality of life dimension not captured by earnings statistics.

The welfare distribution effects of deregulation become magnified when a country falls into a recession but even without an economic slow-down, the 
effects could be sustained for some time. A recent longitudinal study in Australia, using the Four Waves of HILDA to follow the labour market circumstances of lowpaid workers (earning less than $2 / 3$ of median hourly wage), found evidence of a 'low-pay no-pay cycle', with those in low-paid employment in one year 7 times more likely to be in low-paid employment, and two to three times more likely to be unemployed, a year later than those who were in higher paid work (Scutella, 2006).

If NLM were the only effective means of reducing the jobless rate among disadvantaged persons of working age (active or inactive), one would need to take account of these positive social effects on the jobless in the overall evaluation. However, as we shall see, there are other, equally effective means available to governments of achieving the desired employment targets.

\section{Four Possible Responses by Economists}

Against this background, we now consider four alternative stances an economist can take if asked for advice on how to address the distribution effects of NLM.

One response could be to focus only on the economic efficiency implications (what the reform will do to aggregate employment, output and consumer welfare) and assume that the gains will be 'fairly' distributed across the population in the long term. Thus a new NLM initiative would get a tick if it had significantly positive economic effects, irrespective of its short term distribution effects. We call it the efficiency only approach.

A second approach might be to seek to integrate distribution effects into the economic evaluation process by requiring a higher economic return (a 'loading') where the distribution effects are regressive. Under this approach, NLM would only be recommended if it met the higher hurdle rate. We call this approach the integrated approach.

A third response might be to recommend that the NLM reform proceed (because of its positive economic implications) but only on the condition that the tax/transfer system is used to directly compensate losers. This would mean accepting the risk that the 'passive' redistribution process might have adverse incentive effects and claw back some of the potential efficiency gains. This approach can be called the equity first approach.

A fourth approach would be to propose an alternative to NLM - one which would cushion or offset NLM's regressive effects without requiring any significant sacrifice of efficiency or employment. This would mean striving, as with the third approach, towards a pure 'Pareto optimal' (no losers) outcome - but through a more economically benign policy route than passive compensation. This approach can be called the efficiency and equity approach.

Response 1: The efficiency only approach

The first option is simply to focus on efficiency - total economic welfare or aggregate utility - and ignore intermediate distribution effects. 
At the risk of over-simplification, advocates of this approach argue that:

- it is reasonable to assume rational individuals successfully maximise their own utility in the market place;

- GDP can be taken as a broad indicator of the sum of the individual preferences of citizens;

- there is plenty of evidence that NLM can increase GDP per capita over a period of time, so it meets the aggregate utility test;

- any attempt at redistribution would involve making unacceptable inter-personal comparisons of utility;

- redistribution has such high economic costs that it would prove counter-productive even for the poor;

- the benefits of NLM should 'trickle down' to everyone in due course and in the meantime there is a firm welfare safety net in place to protect losers from undue hardship.

The welfare test that is being implicitly applied here is the so-called 'HicksKaldor compensation principle'. It says that a reform is justified so long as the winners are capable of compensating the losers and still remain better off than before. Under this formulation, all that is needed is that the potential be there to compensate losers without actually having to compensate them.

This approach has three advantages. One is simplicity. By looking only at two aggregate consumption (production) equilibriums - the starting point and the point when the reforms have had their full effect - it is able to ignore short term, transitional adjustment costs. And by implicitly assuming that a dollar's worth of gain to one individual deserves the same utility weight as a dollar's worth of loss to another, it is also able to side-step the distribution issue. Under this approach, economists can avoid the complex task of trying to determine winners and losers.

For economists, a second appeal of this approach is that it allows them to do what they are best at without having to intrude into other disciplines (a kind of 'horses for courses' argument).

The third argument for it is that as 'equity' is a multi-dimensional concept, it would be wrong to simply focus on income distribution (an issue we revisit below).

On the other hand, the 'efficiency only' approach is open to four serious objections.

The first is its undue focus on estimated long term GDP gains. By simply looking at two equilibrium positions, it ignores the timing of benefits and losses and transitional adjustment costs.

More fundamentally, the link between GDP and aggregate utility is not as strong as the proponents of this approach imply.

Apart from the fact that our consumption habits are often based on inadequate information about prices and quality and on non-price considerations such as rules of thumb, attitudes of peers and advertising pressure, GDP is limited by convention of national accounting and only captures the wellbeing which results from the production and consumption of goods and services, ignoring non market transactions such as household or community-based activities that are not sold. More importantly, it fails to adjust for consumption (and associated 
production) which has negative effects on third parties such through pollution of the environment or through socially undesirable spending activities. For example, a GDP gain from NLM can involve an involuntary reduction in leisure, a loss of employee control over working hours, a decline in the quality of personal relationships in the workplace and at home or an increase in workers' perceived sense of income uncertainty and insecurity.

To be fair, GDP is a common benchmark employed in much of the public policy literature. But its use creates special problems for an approach which targets aggregates only and ignores quality of life effects.

A second fundamental deficiency of the 'efficiency only' approach is that it does not, as its proponents claim, avoid interpersonal utility comparisons. What it is doing is effectively assigning the same marginal utility weighting to rich and poor, implicitly assuming that an equal transfer of income from poor to rich has no effect on the aggregate sum of their satisfaction - a value judgment no less arbitrary, and in many ways less defensible, than one that assumes the poor have higher marginal utilities. As one of the fathers of modern welfare economics, Little (1957), put it, 'scarcely anyone would want to say that all changes such that the gainers could over-compensate the losers, must be good. For most people it would depend on who the uncompensated losers were' (p. 93). This is not to deny that equity issues are hard to debate objectively (noted below).

Behavioural economics studies consistently show that, although people with more income tend to be somewhat happier than those with less, an extra dollar has a higher value to a poor person than a rich person and that as people become richer, they need progressively bigger increases in income to buy an extra percentage point of happiness. Once their incomes rise above the mean, further increases do not make people much happier unless they markedly out-perform their peers. Behavioural studies also show that the fraction of time spent in an unhappy (unpleasant) state is greater on average for low income households than high income households and that people react more strongly to potential losses than to equal sized potential gains (Tversky and Kahneman, 1981; Treasury, 2004:10-11; Eurak, 2006; Kahneman and Krueger, 2006:20; Gittins, 2007:236ff).

If the benefits of NLM are very unevenly spread across social groups with different utility functions, the 'efficiency only' approach is not necessarily welfare maximising. Even if NLM increased aggregate wellbeing - it may not if the pain suffered by losers exceeds the pleasure accruing to winners - it would not, in the absence of redistribution, necessarily maximise it. That is, it may be possible through a redistribution of the gains from winners to losers to achieve more optimum conditions of production and exchange.

Moreover asking the victims of policy reform to shoulder the whole cost when everyone else benefits is likely to be damaging to social cohesion and to community attitudes to future reform.

$A$ third weakness of the efficiency only approach is its implicit assumption that the benefits 'trickle down' to everyone in due course and in the meantime there is a firm welfare safety net to protect losers. It may well be that everyone benefits over the long term but on the US experience (where more than 90 percent of the gains from economic growth over the last quarter of a century have gone to the richest 10 per cent of the population), the trickle-down effects are 
often slow and uncertain. And, while Australia's welfare safety net is effectively targeted, the benefits provided are far from generous (Whiteford, 2006).

$A$ fourth problem with the efficiency-only approach is its dubious claim that any redistribution would be so economically counter-productive as to ultimately hurt the poor. This argument lacks credibility. We argue later that redistribution has the potential to slow down economic growth but it need not if market-friendly and productive methods of redistribution are used, a minimum level of labour market freedom is maintained and the scale of change is slow and gradual.

Despite its many deficiencies, the 'efficiency only' approach is very popular among economists and in this paper it will be treated as the 'baseline' option.

\section{Response 2: The integrated approach}

Economists who are asked for advice on NLM could try to explicitly build the distribution effects into their overall evaluation by assessing how the benefits and costs of the reform are spread across social groups and then giving appropriate weights to winners and losers according to their likely marginal utilities. Suppose the minimum hurdle rate for a Pareto-optimal reform (making some better off and no one worse off) is an increase in GDP per head of $X$ per cent (in discounted present value terms). For reforms with highly regressive distribution effects, the minimum hurdle rate could be set at say $X$ plus $Y$ with $Y$ being the loading.

What this approach does is redefine the efficiency-equity trade-off by insisting that society should only tolerate a decrease in the utility of the poor if it is associated with a much larger than normal increase in aggregate utility. If a reform like NLM met the higher hurdle rate, it could proceed without compensation. That approach would not prevent an increase in inequality but if the expected economic gains are abnormally large, the likelihood of trickle down effects to the poor is that much greater.

The idea is a sensible one in principle. It would force governments to examine closely the distribution effects and to recognise that an economic reform which is socially disruptive should be treated with more caution than one that is not disruptive. It could also have a high degree of public support as most Australians, if asked, would accept that the pain suffered by each low income loser for every dollar foregone would be greater than the satisfaction gained by well-off winners from each additional dollar consumed. In practice, however, it would be beyond an economist's capacity to make precise assessments of relative marginal utilities, especially when the winners and losers are hard to identify. The ultimate choice of loading (weighting for distribution) would have to be left to the Government's 'political judgment'. This would inevitably end up being arbitrary, and consequently the integrated approach might produce (at the political level) a very similar outcome as the efficiency only approach.

For these reasons, the idea will not be pursued further in this paper.

Response 3: The equity first approach

Some economists might accept that NLM should proceed unhindered and undiluted but insist that every attempt should be made to compensate fully the 
losers, especially those already disadvantaged, through the tax/transfer system even if that meant foregoing some of the potential efficiency gains.

To distinguish this response from 'response 4' discussed below, we assume that the method of compensation used here is 'passive' in character. That is:

- it relies principally on additional cash social security transfers (over and above existing social security benefits) or tax offsets;

- the assistance is offered unconditionally (except for a means test and a requirement to search for work); and

- it is principally intended as a palliative.

One example of this type of response was the Howard Government's tax and social security compensation package associated with the introduction of the goods and services tax. Another example was the set of proposals put by the socalled 'five economists' in the late 1990's which included a freeze on the minimum wage with compensation for low-paid households with tax credits or offsets (Dawkins, 2001). Again, the idea of wage insurance, which is discussed later, is a form of compensation for pay losses suffered as a direct result of reforms which facilitate retrenchment of workers. In all these cases, the compensation is seen as desirable principally on equity grounds and does not require any offsetting obligations from recipients.

The objectives of policy response 3 (equity first) are laudable - to spread the gains of NLM more widely across the population and strive for a Pareto optimal outcome.

The problems are twofold. One is that it is only feasible where the losers are clearly identifiable and their losses can be quantified. In practice many of the people adversely affected by NLM cannot be specifically targeted even if the focus is only people of low socio-economic background. In any case, while fiscal measures can compensate for wage inequalities, they cannot effectively make up for a decline in workers' quality of life due to loss of workplace control and family time.

The other problem is that increases in passive welfare and taxes can create perverse economic incentives in regard to work, saving and employment. Advocates of this approach see the trade-offs in less stark terms than those who embrace the 'efficiency first' approach but they accept that some efficiency may have to be sacrificed.

For these various reasons, the equity first option, while having merit, is not discussed further in this paper.

\section{Response 4: The efficiency and equity approach}

Another possible response might be to go back to the drawing board and look for a new policy mix which can achieve the same goals as NLM but with a better balance between efficiency and distributional equity. This is the fourth and last option - and potentially the most rewarding because it aims to maximise both efficiency and distributional equity.

The principal objective of the NLM reforms is to lift labour participation rates. It achieves its ends by allowing more room for downward wage flexibility, giving 
managers greater autonomy in hiring and firing and tightening welfare access, while reducing the role of collective bargaining and regulation.

An alternative strategy can be called 'liberal-interventionist' or LI. It would retain most elements of the liberal economy built up over the last thirty years. For example, welfare support for able-bodied people would remain conditional on actively searching for work or training (with appropriate penalties for breaches). There would still be plenty of structural wage flexibility, so that wages can remain sensitive to shifts in relative productivity and structural change. And managers would retain a considerable degree of autonomy in hiring and firing (to allow firms to respond quickly and effectively to changes in market conditions).

However LI departs from the NLM agenda (completely free labour markets) in three ways.

First, it would offer extra compensation to workers who were forced by the policy change into lower-paid jobs. For example it could incorporate a system of wage insurance or temporary wage supplements for older workers who are retrenched as a consequence of $\mathrm{LI}$.

Second, it would be more tolerant of social and workplace regulation, where such regulation was considered necessary to avoid creating a large population of welfare-dependent 'working poor' and where it was considered the only effective way to protect important values such as employees' right to bargain collectively and control their working hours and family time.

Third, and most importantly, the LI agenda would rely as much on social spending as on deregulation to achieve its employment objectives. The spending would be on productive ('active') social programs - those which enhance human capital and help correct labour market imperfections (such as geographical immobility). In particular, under LI, the government would invest in:

- measures to correct early childhood disadvantages;

- improved access to employment-enhancing services such as health, public education and public transport in low-income areas;

- remedial programs for older school children and youth who are under-performing;

- $\quad$ adult retraining and life long learning programs;

- well-funded job search and placement services, personal case management and assistance with career development;

- $\quad$ wage subsidies targeted at the low-skilled group;

- $\quad$ targeted job-creation in the community and public sector; and

- family-friendly policies such as flexible working patterns, paid parental leave and good quality and affordable child care assistance.

As well, on the supply side, it would use tax credits (in-work bonuses) to ensure that inactive people of working age had adequate financial incentive to move from welfare to work and offer more generous relocation assistance to reduce the geographical mismatch between job vacancies and job seekers.

LI programs have two distinctive characteristics. They are prepared to sacrifice some of the economically rewarding neo-liberal elements of NLM where these have potentially very damaging effects on inequality. And they involve a retreat from the more traditional methods of passive redistribution which have damaging effects on efficiency, relying instead on 'active' redistribution measures. 


\section{Evaluating Response 4 Relative to Response 1}

In this section, we evaluate response 4 relative to response 1 . We know that well-designed LI programs - outlined in the previous section - can produce lower inequality and higher mobility (Argy, 2006). Thus, on the equity criterion most used by economists, that is, vertical distribution, response 4 wins out.

But does it involve a heavy economic sacrifice? In particular, given its high initial demands on taxpayers, what does it do to the dynamism of the economy employment, productivity and per capita incomes growth? This is the issue discussed here.

Higher tax levels can damage economic efficiency if (a) they weaken incentives (for example, induce people to work less and take fewer risks) (b) force people into less preferred choices (causing personal welfare losses) and (c) impose additional administrative and compliance costs. However, the effects of redistribution depend heavily on the starting point (the tax and spending levels), the scale of the increase in taxes required and the methods of redistribution used.

A standard proposition in economics is that the 'deadweight loss' (choicedistorting, welfare-reducing effect) of a tax tends to increase approximately with the square of the tax rate: if we double the size of tax, deadweight loss increases four-fold and if we triple the size of the tax, the deadweight loss increases ninefold (Gans, King and Mankiw, 1999:160-162). Low tax countries like Australia, therefore, can be expected to suffer less than high tax countries from an increase in the scale of redistribution, provided it is gradual.

The method of redistribution used is also crucial. For example, if governments seek to advance social goals through direct budgetary methods, the adverse effects on efficiency are much less significant than if governments used rent controls, restrictions on trade, directions to banks or elaborate and extensive labour market regulations to achieve their distribution goals. More importantly, while passive fiscal redistribution can create perverse economic incentives in regard to work, saving and employment, this is not true of 'active' social investment and work-related incentives (depending on budgetary methods used).

Whereas passive assistance merely seeks to temper the effects of market change on persons and regions, active redistribution seeks to make markets function more effectively. Even a completely deregulated labour market does not adjust quickly and efficiently to shocks because of barriers to geographical and occupational mobility, imperfect or asymmetric information and a tendency for credit markets to be biased against asset-poor people with irregular incomes (and thus limiting access to finance for human capital formation). There is also often monopsonist power in the markets for certain kinds of human capital or locations, and workers do not have the flexibility to adjust their labour supply at the margin.

Once we move into the realm of 'second best' decisions in economics, the welfare outcome from free labour markets becomes more uncertain. By addressing market failure, $\mathrm{LI}$ programs can produce a better match between job vacancies and job-seekers, improve workforce participation and reduce the risk of a long term loss of employability.

This view has strong empirical support. Countries which tightly regulate their economies and spend heavily on passive (unconditional) redistribution, with high 
tax levels, suffer from slower economic growth than those which rely heavily on labour deregulation and low government spending. However, in between we find a large cluster of countries that use a mix of market-freeing policies, moderate regulation and relatively high levels of 'active' government social spending without suffering any significant economic penalty. That is, beyond a certain level of labour market freedom, correlation between levels of redistribution and economic growth becomes inconclusive either way (Arjona, Ladaique and Pearson, 2001; Pressman, 2005; Perotti, 1996; Smeeding, 2005; and Rehme, 2006).

Smeeding's (2005:12 and 17-19) literature review makes two salient points: (a) social programs such as those adopted by the Nordic countries are effective in reducing inequality; and (b) there is no evidence that the stronger economic performance of the US and UK in the last ten years, relative to many other OECD countries, was caused by their lower levels of social spending. Quiggin (2006:52) writes: 'the general consensus of the literature is that there is no well-established relationship between economic growth and aggregate levels of government expenditure'. Decomposition of government expenditure, for example, shows that government investment in both physical infrastructure and human capital increases subsequent growth. This may explain why economists cannot find any correlation between size of government and economic growth per capita (Caserta, 2007) - obvious anyway from a scatter diagram of all the developed countries.

In short, both theory and empiricism suggest that the LI strategy, correctly implemented, can be economically benign. It is capable of delivering work force participation outcomes comparable to those produced by NLM (Argy, 2007) - for the obvious reason that it specifically targets potentially disadvantaged workers. Nor does it seem to adversely affect productivity and per capita income growth.

The productivity outcome might appear counter-intuitive to many classical economists. So it is worth speculating why response 4 does not suffer on the productivity front relative to response 1 . One reason is that the 'efficiency only' approach, which relies principally on NLM, is not all positive for productivity. Labour market deregulation implies more flexibility in resource management within the enterprise and that is a plus relative to the alternative. However as it relies heavily on a reducing input costs to employers to facilitate the entry of lowproductivity 'fringe' workers into employment, it must inevitably lead to a lowering of average labour productivity. Greater flexibility also gives employers less incentive to improve efficiency since they can readily cut wage costs instead. In addition, it could have adverse effects on employee team spirit and morale (Argy, 2007). There are conflicting forces at work and the net effect on national productivity of the 'efficiency only' approach is uncertain.

Much the same can be said of the 'equity and efficiency' approach which relies at least as much on interventionist policies as on deregulation. On the one hand it involves a strong investment in human capital with good pay-offs in the long term (as noted earlier). On the other hand, until the programs start to pay for themselves, LI requires higher taxation, with potential effects on incentives and innovation. As noted earlier the adverse effects of higher taxes can be minimised by relying on revenue base-broadening measures which have a minimal distorting effect on choices and incentives. But higher taxes must leave some residual cost, even for a low-tax country like Australia. 
Thus, the net effect on productivity of the efficiency and equity approach, like the NLM approach, is uncertain and it is hard to choose between them on this criterion.

\section{Some Complexities About the Meaning of Equity}

If the above analysis is correct, the choice between response 1 and response 4 must rest ultimately on social value judgments rather than on economic considerations. Since response 4 produces less vertical income inequality, shouldn't it be the preferred option of economists?

Unfortunately the story is not so simple. Apart from inevitable analytical disagreements among economists about the economic effects of $\mathrm{LI}$ relative to $\mathrm{NLM}$, there is also a need to take account of elements of equity other than vertical income distribution.

The kinds of equity goals that are important to Australians (Argy, 2006:5156) and need to be considered in any evaluation of a proposed policy reform are that:

- the reform should not adversely affect the well-being (income, quality of life or opportunity for advancement) of the poorest and most vulnerable in the community;

- it should be consistent with equality of opportunity;

- $\quad$ it should not discourage individual responsibility and self-reliance;

- $\quad$ and it should not unduly impede individual freedom of choice and action.

As already discussed, LI meets the first criterion better than the neo-liberal agenda. Moderate labour market deregulation is compatible with a stable distribution of final incomes if it is matched by appropriate tax-transfer and social investment policies. But the more reliance a government places on deregulation to deliver good employment outcomes, the greater the likelihood that the poor will come out losers.

Australians also attach great importance to quality of life and perceived stability of incomes. Here, LI scores well too. Under the neo-liberal option, lowskilled, disadvantaged workers lose some control over their working hours and family time and their income becomes more uncertain (more exposed to downgrading or dismissal). Income and hours uncertainty following a program of deregulation is damaging to happiness and trust and could create a climate of hostility to further economic reform in the future. LI is less open to these risks.

The second equity dimension is equality of opportunity - the notion that everyone should be able to develop their full potential irrespective of the original circumstances of their birth and childhood and people's earnings prospects should be determined overwhelmingly by their own ability and character. This notion captures best what Australians mean by 'fair go' (Argy, 2006).

On this criterion, the advantage is again with $\mathrm{LI}$, although more marginally. The neo-liberal strategy (NLM) widens the role of impersonal markets, allowing earnings outcomes to be more freely determined by an open competitive process. But even in the most competitive markets there are many barriers to income mobility (Argy, 2006). LI strives hard to reduce these barriers for example by reducing early family environment and education inequalities. It thus enhances 
the ability of low income people to move up the income and occupational scale during their lifetime.

However, and here we come to the third dimension of equity, Australians hate 'bludgers'. They want people to 'have a go'. Here, the balance of advantage may perhaps shift to the neo-liberal strategy, but not by much. Response 1 certainly leaves more room for personal responsibility and self-reliance. But response 4 tries hard to encourage the acquisition of human capital and selfconfidence, without which people are unable to develop self-reliance. It also tries hard to encourage self-help and discourage a welfare culture.

The fourth dimension of equity is individual freedom of choice and action the idea that people should be left to lead their own lives according to their own idea of what is good, so long as they do not harm others. Response 1 has again a slight advantage here as taxes are lower. But individual 'freedom' is an elusive concept. It is not just about the right of an individual to retain what he or she earns or produces and to choose from the consumption possibilities in the market. It is also about capability - the ability to participate actively in society (positive liberty) and overcome barriers to reaching their full potential (Sen, 1992). From the latter viewpoint (encompassed in the equal opportunity goal) response 4 offers a superior product. It widens the range of longer term employment opportunities and choices available to low-paid and jobless workers affected by structural change and make it easier for them to achieve their full potential.

Based on the results of opinion surveys (outlined in Argy, 2006:51-56) and the consistent and fairly strong majority opposition to the recent IR reforms, even by people who do not expect to be worse off themselves (for example, ACNielsen poll 19/6/06), it is reasonable to say that a majority of Australians would see the LI strategy as more equitable than NLM. But one cannot be sure!

\section{Concluding Observations}

The paper has examined four possible responses to a radical program of labour market deregulation and welfare reform (what we called NLM). It ruled two of them out on practical as well as economic or social grounds, thus narrowing the policy choice to one between response 1 (efficiency only) and response 4 (efficiency and equity). These two responses were then compared on the usual criteria of employment, productivity, distributive justice and other equity goals.

It concluded that both responses had the potential to produce good employment and productivity outcomes but markedly different social outcomes. The fourth response (with active social investment in human capital as the critical method of redistribution) is clearly superior on distributive justice and equality of opportunity criteria to the first response (with deregulation as the main policy weapon) but it may not do as much for choice and self-reliance. So it all depends on which mix of social values appeals most.

This is a very inconclusive position to arrive at. Yet there are two important messages in this paper. The first is that it is not good enough to evaluate a policy reform by simply comparing two equilibrium points - for example, 'GDP will be $x$ per cent higher once the full effects of the reform have occurred' (which could be a decade later) - and pronounce it to be a 'desirable' reform without taking account of how the benefits are distributed and the transitional adjustment costs 
and without declaring where their own values lie. When economists do this, they are producing a very incomplete analysis and giving the profession a bad name.

This is not to argue that economists should scrupulously avoid value judgments. They are as entitled as anyone else to make value-based policy recommendations. But they should be transparent about them. Fortunately, if they don't, other economists will see through them. As the famous British economist J oan Robinson said, 'the purpose of studying economics is to learn how to avoid being deceived by other economists'.

The second message from this paper is that, while economists should avoid dogma when approaching policy ideas involving equity redistributions, they still have a major role to play in resolving equity/efficiency or equity/equity trade-offs.

For one thing, they can help governments identify the set of alternatives or choices that are available to society (the realistic choices or sacrifice ratios). There is still much work still to be done on the effects of various market liberalisation reforms on distribution (which types of reforms are progressive and which regressive), the efficiency effects of redistribution (which instruments of redistribution are most efficiency-friendly) and the still unresolved relationship between inequality and economic performance.

Again, and most importantly, economists should continue to explore, at the micro level, the social effectiveness of alternative government social programs for example how effectively job training programs boost employment and earnings, whether universal pre-school education enhances future education results and work force participation and so on. This means looking at the experience and research results in other countries as well as Australia. It also means making greater use of randomised trials and experiments.

And, more controversially perhaps, there is a role for economists in ensuring that policy advice proffered is sensitive to community preferences and grounded in reality. So they need to do more to understand community attitudes to equality and freedom and the 'gap' between community aspirations and reality. This would mean asking economists to work on issues which are at the periphery of their discipline and best done in conjunction with other sociologists - but it would be no more than an extension of the mushrooming field of behavioural economics.

\section{References}

Argy, F. (2005), 'An Analysis of J oblessness in Australia', Economic Papers 24(1):75-96.

Argy, F. (2006), 'Equality of Opportunity in Australia - Myth and Reality', The Australia Institute, Discussion Paper No. 85, April.

Argy, F. (2007), 'Employment Policy and the Clash of Values', Public Policy 1(2):61-82, (John Curtin Institute of Public Policy).

Arjona, R., M. Ladaique and M. Pearson (2001), 'Growth, Inequality and Social Protection', Organisation for Economic Co-operation and Development, Occasional Paper No. 51, June.

Borland, J. (2000), 'Economic Explanations of Earnings Distribution,' NZ Treasury Report, Wellington.

Breusch, T. and Wilson, S. (2004), 'After the Tax Revolt', Australian Journal of Social Issues 39(2):99-114. 
Caserta, J. (2007), 'Digging Deeper into Heritage Foundation Data', blogspot.com/2007-0501-archive.html, 7 February.

Dawkins, P. (2001), 'The Five Economists Plan', paper presented to a Melbourne Institute/ANU Conference, September.

Eurak, A (2006), 'How Does your Brain Respond when you Think about Gambling or Taking Risks?', Science 26 J anuary.

Forster, M. and M. d'Ercole (2005), 'Income Distribution and Poverty in OECD Countries in the Second Half of the 1990s', OECD, Social, Employment and Migration Working Paper No. 22.

Gans, J, S. King and G. Mankiw (1999), Principles of Microeconomics, Harcourt Brace, Sydney.

Gettler, L. (2006), 'Are Researchers Happy with Search for Happiness?', Sydney Morning Herald 4 August.

Gittins, R. (2006), 'An Economics Fit for Humans', The Ronald Henderson Oration, Melbourne, 5 August.

Gittins, R. (2007), Gittinomics, Allen and Unwin, NSW.

Jencks, C. (2006), 'Inequality: How Much is Too Much', Paper presented to Research School of Social Sciences conference, ANU, 2 November.

Little, IMD (1950), A Critique of Welfare Economics, Oxford Paperbacks, London.

Luciforo, C. (1999), 'Wage Inequalities and Low Pay: The Role of Labour Market Institutions', Facolta di Scienze Politiche, Paper presented to seminar at University of Napoli, November 1998.

Martin, J. (2006), 'Globalisation and Jobs: What Policies?', OECD Observer, October.

Perotti, R. (1996), 'Growth, Income Distribution and Democracy: What the Data Say', Journal of Economic Growth 1:149-187.

Pressman, S. (2004), 'The Decline of the Middle Class: An International Perspective', Luxembourg Income Study, Working Paper No. 280, Economics and Finance Faculty, Monmouth University.

Quiggin, J. (2006), 'The End of the Public Sector Debate', pp. 49-61 in C. Sheil (ed.), The State of the Public Sector, Evatt Foundation, Sydney.

Rehme, G. (2006 ), 'Education, Economic Growth and Measured Income Inequality', Luxembourg Income Study, Working Paper No. 428, February.

Saunders, P. (2002), The Ends and Means of Welfare, Cambridge University Press, Melbourne.

Scutella, R (2006), 'Unemployment and Low-Paid Work', Brotherhood Comment (www.bsl.org.au), November 2006.

Sen, A. (1992), Inequality Re-Examined, Harvard University Press, Cambridge.

Smeeding, T (2005), 'Poor People in Rich Countries: The United States in Comparative Perspective', Luxembourg Income Study, Working Paper No. 419, October. 
Treasury (2004), 'Policy Advice and Treasury's Wellbeing Framework', Background paper presented to the Australian Statistics Advisory Council, Canberra, 25 May.

Treasury (2005), 'Prosperity and Sustainability', Statement No. 4, Budget Paper No. 1, Canberra.

Tversky, A. and D. Kahneman (1981), 'The Framing of Decisions and the Psychology of Choice', Science 211(4481):453-458.

Whiteford, P. (2006), 'The Welfare Expenditure Debate - Economic Myths of the Left and the Right Revisited', Address to ANU seminar.

The author wishes to thank two referees and Graeme Wells for their helpful suggestions and criticisms. 
